\title{
Curious case of corpus callosal hematoma in a normotensive post- partum female patient: a case report of reversible post-partum angiopathy with clinico-radiological correlation
}

\author{
Gaurav Chauhan ${ }^{1}$, Vivek Singh ${ }^{1 *}$, R. V. Phadke ${ }^{1}$, Sapna Yadav $^{2}$, Abhishek Gupta $^{1}$
}

\begin{abstract}
${ }^{1}$ Department of Radio-diagnosis, ${ }^{2}$ Department of Neuro-Anaesthesia, Sanjay Gandhi Post Graduate Institute of Medical Sciences, Lucknow, Uttar Pradesh, India
\end{abstract}

Received: 06 June 2018

Accepted: 29 June 2018

\author{
*Correspondence: \\ Dr. Vivek Singh, \\ E-mail: singhvivek79@rediffmail.com
}

Copyright: () the author(s), publisher and licensee Medip Academy. This is an open-access article distributed under the terms of the Creative Commons Attribution Non-Commercial License, which permits unrestricted non-commercial use, distribution, and reproduction in any medium, provided the original work is properly cited.

\begin{abstract}
Postpartum cerebral angiopathy (PCA) is a rare cause of stroke in the puerperium. It usually presents with episodes of headache, seizures and neurological deficits in early post-partum period in normotensive females. CT, MRI and catheter angiography may demonstrate segmental vasoconstriction that often resolves spontaneously. PPA is generally regarded as a benign, non-relapsing and reversible disease process. We present a clinico-radiological correlative case of isolated corpus callosal hematoma in a post-partum normotensive female with evidence of intracranial vascular spasm and luminal irregularity on CT and catheter angiography. Follow up MR angiography showed resolution of the vasospasm and luminal irregularity. Patient was managed conservatively and showed resolution of the symptoms in follow up visit on $8^{\text {th }}$ week.
\end{abstract}

Keywords: Angiopathy, Cerebral artery, Postpartum, Reversible, Vasoconstriction

\section{INTRODUCTION}

The occurrence of ischemic stroke in postpartum period is uncommon. PCA is a reversible, non-relapsing clinicradiological syndrome which is characterized by onset of acute headache, focal neurologic deficits and reversible cerebral segmental vasoconstriction. ${ }^{1}$ Angiography demonstrates areas of multifocal and segmental narrowing in medium and large sized cerebral arteries, appearance akin to vasculitis. ${ }^{2}$ The process is usually selflimiting, with resolution of vasoconstriction within 4-12 weeks of onset along with complete resolution of symptoms. $^{3}$ However due to its association with intraparenchymal hemorrhage and infarction, PCA carry a significant risk of morbidity and mortality. ${ }^{4}$

PCA comes under the large umbrella term of reversible vasoconstriction syndromes (RCVS), characterized by reversible vasoconstriction of the cerebral arteries. ${ }^{5}$ RCVS consists of large group of different clinical entities with nearly similar clinical presentation and radiological appearance. Although the patho-physiology of RCVS remains unknown, the prevailing hypothesis suggests a transient disturbance in vascular tone. ${ }^{6}$ This alteration in vascular tone may be spontaneous or evoked by various exogenous or endogenous factors. Pregnancy-related hormonal effects are known to alter vascular tone. ${ }^{7}$

\section{CASE REPORT}

We report a case of 29-year-old multi-para female who presented with severe headache and two episodes of focal seizures on $10^{\text {th }}$ post-partum day. She has been normotensive throughout the antenatal period and delivered a healthy baby on $37^{\text {th }}$ week and $5^{\text {th }}$ day of gestation via normal vaginal delivery. Latest antenatal 
ultrasound showed grade II placenta and amniotic fluid index (AFI) of $13 \mathrm{~cm}$. Her lab investigations and physical examinations were with-in the normal limits.

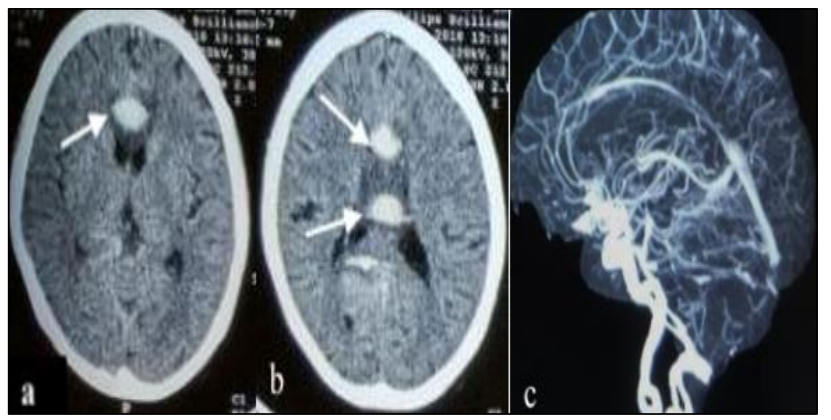

Figure 1: NCCT head showed hematoma (arrows in a and $b$ ) in the genu and body of the corpus callosum.

CTA (c) showed multifocal spasm and luminal irregularity in the intracranial vasculature.

Non-contrast CT head was done to rule out the cause of headache and seizures, which showed corpus callosal hematoma in the region of the genu and body with locoregional edema (Figure $1 \mathrm{a}$ and $\mathrm{b}$ ). To rule out the underlying cause, CT angiography was done in the same sitting, given the normal serum creatinine levels, which showed spasm in the intracranial vasculature along with mild luminal irregularity in the anterior and posterior circulation vessels (Figure 1c).

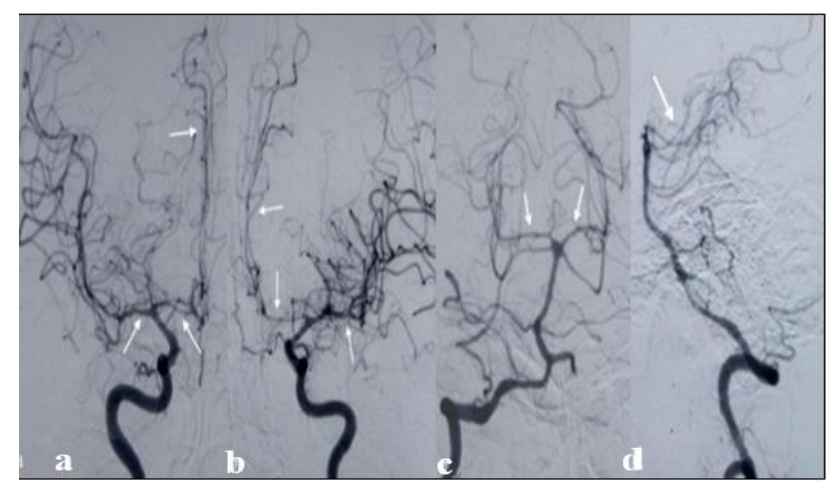

Figure 2: No evidence of aneurysm noted in intracranial vessels. Significant vasospasm with mild luminal irregularity (arrows) in bilateral anterior, middle and posterior cerebral arterial vasculature.

Catheter angiography was done to exclude the remote possibility of the ruptured distal anterior cerebral artery (DACA) aneurysm. Catheter angiography showed no evidence of aneurysm in anterior or posterior circulation, however it revealed significant vasospasm with mild luminal irregularity in bilateral anterior, middle and posterior cerebral arteries and their branches (Figure 2a, b, c and d).

Patient was managed conservatively and symptomatically under maternal and reproductive health department and during this period patient's symptoms resolved gradually.
MRI was done after a follow up period of 9 weeks, which showed subtle T2/Flair signal changes in the corpus callosum with blooming on gradient echo sequence suggestive of hemosiderin residue (Figure $3 a$ and $b$ ).

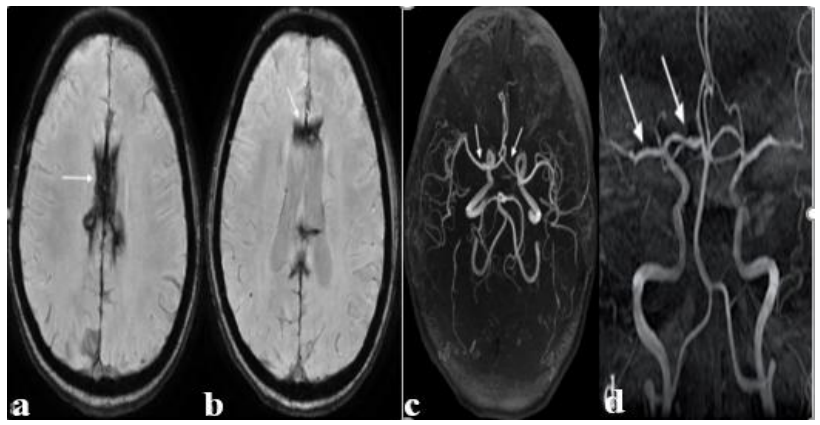

Figure 3: SWAN sequence shows hemosiderin residue in the corpus callosum suggestive of old hematoma (a, b). MRA shows normal and smooth luminal caliber of the intracranial vessels suggestive of reversibility of the disease process $(\mathrm{c}, \mathrm{d})$.

MR angiography showed normal luminal caliber of the intracranial vasculature including anterior and posterior circulation (Figure 3c and d). No e/o any residual luminal irregularity or narrowing was noted in the current scan, justifying its reversible nature. As for now, the patient is asymptomatic and under clinical follow up.

\section{DISCUSSION}

PCA is a poorly understood cerebro-vascular disorder that occurs in normotensive postpartum women within $1^{\text {st }}$ to $4^{\text {th }}$ post-partum weeks. Two recognizable forms of PCA has been described in literature. Idiopathic PCA, also known as call-fleming postpartum angiopathy, is a reversible non-relapsing angiopathy that occurs in normotensive postpartum women presenting with severe headache, seizures, and focal neurologic deficits due to intracerebral hemorrhage. ${ }^{8,9}$ Iatrogenic PCA may occur during the puerperium after administration of various drugs i.e. bromocriptine, ergot alkaloids or sympathomimetics. ${ }^{10}$ The diagnosis of PCA should be sought after in normotensive postpartum women presenting with intracerebral hemorrhage. Patients with PCA may also show reversible T2 hyperintense signal abnormalities in cerebral parenchyma. The angiographic features are characteristic and are typified by reversible multifocal area of luminal narrowing and beaded appearance of the medium and small caliber cerebral arteries, predominantly in the anterior circulation. ${ }^{11}$ This is in contradistinction to eclampsia, which affects large and medium-sized arteries in the posterior circulation.

The exact patho-physiology of RCVS is not clearly understood. Due to its typical rapid clinical recovery and resolution of vasoconstriction, pathological correlation has not been fully studied. Transient disturbance in the auto regulation of cerebro-vascular tone has been hypothesized as the most plausible cause which may be 
spontaneous or due to exposure of vasoactive substances. ${ }^{12-14}$ It has also been suggested that female reproductive hormones and pregnancy-related physiological changes could result in transient alterations of cerebral vascular tone. ${ }^{15}$ These physiological changes include increased blood volume, arterial stiffness, generalized vasodilation, impaired glucose tolerance, mild systemic inflammation along with decreased peripheral vascular resistance and blood pressure. ${ }^{16}$

Radiological investigations for post-partum patients presenting with acute severe headache should include a non-contrast CT head to exclude subarachnoid or intracerebral bleed. CT angiography may be warranted in the same sitting to rule out the cause of bleed and to comment on the status of intracranial vasculature. Typical "string of beads" appearance of the intracranial vessels is characteristic angiographic finding in RCVS. MRI with angiography should be the next radiological investigation following a normal $\mathrm{CT} .{ }^{17}$ In position of the normal CT angiography (CTA) and MR angiography (MRA) but with clinical suspicion of RCVS, digital subtraction angiography (DSA) should be done. Follow-up imaging may be done with MRA or DSA to demonstrate and document the reversal of cerebro-vascular vasoconstriction. The important differential diagnosis of RCVS/PCA is primary angiitis of the CNS (PACNS), dural venous sinus thrombosis, aneurysmal rupture which can be differentiated by clinico-radiological correlation and history of the patient. Therapeutic management is conservative and empirical via calcium channel blockers with or without short course of steroid along with magnesium sulphate, not to mention identification and discontinuation of the possible trigger agents. ${ }^{18,19}$ Prognosis is usually good due to the spontaneous resolution.

\section{CONCLUSION}

Postpartum cerebral angiopathy is a peculiar, non relapsing clinico-radiological syndrome characterized by reversible segmental cerebro-vascular spasm associated with or without intracranial hemorrhage in a normotensive post partum females due to diverse etologies as described. Radiology plays an important role to depict and document the hemorrhagic and vascular changes in brain along with the reversible nature of the disease process in follow up period, as highlighted in the current case report.

\section{Funding: No funding sources \\ Conflict of interest: None declared \\ Ethical approval: Not required}

\section{REFERENCES}

1. Fugate JE, Ameriso SF, Ortiz G, Schottlaender LV, Wijdicks EF. Variable presentations of postpartum angiopathy. Stroke. 2012;43:670-6.
2. Ducros A, Bousser MG. Reversible cerebral vasoconstriction syndrome. Pract Neurol. 2009;9:256-67.

3. Ducros A, Boukobza M, Porcher R, Sarov M, Valade D. The clinical and radiological spectrum of reversible cerebral vasoconstriction syndrome. A prospective series of 67 patients. Brain. 2007;130:3091-101.

4. Jaigobin C, Silver FL. Stroke and pregnancy. Stroke. 2000;31:2948-51.

5. Calabrese LH, Dodick DW, Schwedt TJ, Singhal AB. Narrative review: reversible cerebral vasoconstriction syndromes. Ann Intern Med. 2007;146:34-44.

6. Schwedt TJ, Matharu MS, Dodick DW. Thunderclap headache. Lancet Neurol. 2006;5:621-31.

7. Newell CP, Seller C, Vizhi M, Turner N. Case report: Spontaneous coronary artery dissection during elective caesarean section under spinal anaesthesia. Anaesthesia. 2011;66:615-9.

8. Geocadin RG, Razumovsky AY, Wityk RJ, Bhardwaj A, Ulatowski JA. Intracerebral hemorrhage and postpartum cerebral vasculopathy. J Neurol Sci. 2002;205(1):29-34.

9. Neudecker S, Stock K, Krasnianski M. Call-Fleming postpartum angiopathy in the puerperium: a reversible cerebral vasoconstriction syndrome. Obstet Gynecol. 2006;107:446-9.

10. Chartier JP, Bousigue JY, Teisseyre A, Morel C, Delpuech-Formosa F. Postpartum cerebral angiopathy of iatrogenic origin. Rev Neurol. 1997;153(3):212-4.

11. Konstantinopoulos PA, Mousa S, Khairallah R, Mtanos G. Postpartum cerebral angiopathy: An important diagnostic consideration in the postpartum period. Am J Obstet Gynecol. 2004;191(1):375-7.

12. Singhal AB, Hajj-Ali RA, Topcuoglu MA. Reversible cerebral vasoconstriction syndromes: Analysis of 139 cases. Arch Neurol. 2011;68:100512.

13. Thiex R, Norbash AM, Frerichs KU. The safety of dedicated-team catheter-based diagnostic cerebral angiography in the era of advanced noninvasive imaging. AJNR Am J Neuroradiol. 2010;31:230-4.

14. Soltanolkotabi M, Ansari SA, Shaibani A, Singer TB, Hurley MC. Spontaneous post-partum cervical carotid artery dissection in a patient with reversible cerebral vasoconstriction syndrome. Interv Neuroradiol. 2011;17:486-9.

15. Geraghty JJ, Hoch DB, Robert ME, Vinters HV. Fatal puerperal cerebral vasospasm and stroke in a young woman. Neurol. 1991;41:1145-7.

16. Akhter T, Larsson A, Larsson M, Wikström AK, Naessen T. Artery wall layer dimensions during normal pregnancy: A longitudinal study using noninvasive high-frequency ultrasound. Am J Physiol Heart Circ Physiol. 2013;304:H229-34.

17. Chen SP, Fuh JL, Wang SJ. Reversible cerebral vasoconstriction syndrome: An under-recognized 
clinical emergency. Therapeutic Advances in Neurological Disorders. 2010;3(3):161-71.

18. Karmacharya R, Singh M, Rawal S. Call Fleming syndrome: Case report. Nepal J Neurosci. 2008;5:601 .

19. Cvetanovich GL, Ramakrishnan P, Klein JP, Rao VR, Ropper AH. Reversible cerebral vasoconstriction syndrome in a patient taking citalopram and hydroxycut: A case report. J Med Case Rep. 2011;5:548.

Cite this article as: Chauhan G, Singh V, Phadke RV, Yadav S, Gupta A. Curious case of corpus callosal hematoma in a normotensive post-partum female patient: a case report of reversible postpartum angiopathy with clinico-radiological correlation. Int J Reprod Contracept Obstet Gynecol 2018;7:3413-6. 